\title{
Achalasia and acromegaly: Co-incidence of these diseases or a new syndrome?
}

\author{
Jiri Dolina a, Lumir Kunovsky ${ }^{\mathrm{a}, \mathrm{b}}$, Radek Kroupa a, Karel Starya , Petr Jabandziev, ,d, Tereza Nesporovaa, Karel Macae,

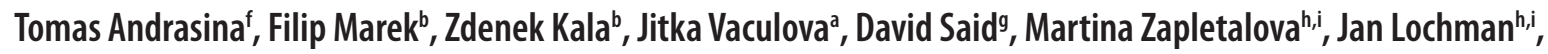 \\ Hana Palova Noskovac, Ondrej Slaby, ${ }^{\mathrm{cj}}$, Lydie Izakovicova Holla ${ }^{\mathrm{h}, \mathrm{k}}$, Petra Borilova Linhartova ${ }^{\mathrm{h}, \mathrm{l}}$
}

\begin{abstract}
Background. Acromegaly is a disorder associated with hypersecretion of growth hormone, most usually caused by a pituitary adenoma. Dysmotility of the gastrointestinal tract has been reported in acromegalic patients. Achalasia is a disorder characterized by aperistalsis of the oesophagus with incomplete lower oesophageal sphincter relaxation and whose aetiology remains unknown. Mutations in some genes have previously been associated with the development of acromegaly or achalasia. The study aims were to analyse mutations in selected genes in a woman having both of these diseases, to identify their aetiological factors, and to suggest explanations for the co-incidence of acromegaly and achalasia.

Methods and Results. A female patient with acromegaly, achalasia, and a multinodular thyroid gland with hyperplastic colloid nodules underwent successful treatment of achalasia via laparoscopic Heller myotomy, a thyroidectomy was performed, and the pituitary macroadenoma was surgically excised via transnasal endoscopic extirpation. Germline DNA from the leukocytes was analysed by sequencing methods for a panel of genes. No pathogenic mutation in AAAS, AIP, MEN1, CDKN1B, PRKAR1A, SDHB, GPR101, and GNAS genes was found in germline DNA. The somatic mutation c.601C $>\mathrm{T} / \mathrm{p}$. R201C in the GNAS gene was identified in DNA extracted from a tissue sample of the pituitary macroadenoma.

Conclusions. We here describe the first case report to our knowledge of a patient with both acromegaly and achalasia. Association of acromegaly and soft muscle tissue hypertrophy may contribute to achalasia's development. If one of these diagnoses is determined, the other also should be considered along with increased risk of oesophageal and colorectal malignancy.
\end{abstract}

Key words: acromegaly, pituitary tumour, achalasia, autoimmune syndrome, gene, mutation, AAAS, GPR101, GNAS

Received: April 10, 2021; Revised: June 3, 2021; Accepted: June 14, 2021; Available online: July 2, 2021

https://doi.org/10.5507/bp.2021.040

(c) 2022 The Authors; https://creativecommons.org/licenses/by/4.0/

${ }^{a}$ Department of Gastroenterology and Internal Medicine, University Hospital Brno, Faculty of Medicine, Masaryk University, Jihlavska 20, 62500, Brno, Czech Republic

${ }^{b}$ Department of Surgery, University Hospital Brno, Faculty of Medicine, Masaryk University, Jihlavska 20, 62500, Brno, Czech Republic 'Central European Institute of Technology, Masaryk University, Kamenice 5, 62500, Brno, Czech Republic

${ }^{d}$ Department of Pediatrics, University Hospital Brno, Faculty of Medicine, Masaryk University, Cernopolni 9, 61300, Brno, Czech Republic eDepartment of Neurosurgery, University Hospital Brno, Faculty of Medicine, Masaryk University, Jihlavska 20, 62500, Brno, Czech Republic ${ }^{f}$ Department of Radiology and Nuclear Medicine, University Hospital Brno, Faculty of Medicine, Masaryk University, Jihlavska 20, 62500, Brno, Czech Republic

${ }^{9}$ Department of Pathology, University Hospital Brno, Faculty of Medicine, Masaryk University, Jihlavska 20, 62500, Brno, Czech Republic ${ }^{h}$ Department of Pathophysiology, Faculty of Medicine, Masaryk University, Kamenice 5, 62500, Brno, Czech Republic

'Department of Biochemistry, Faculty of Science, Masaryk University, Kamenice 5, 62500, Brno, Czech Republic

'Department of Biology, Faculty of Medicine, Masaryk University, Kamenice 5, 62500, Brno, Czech Republic

${ }^{k}$ Clinic of Stomatology, Institution Shared with St. Anne's Faculty Hospital, Faculty of Medicine, Masaryk University, Pekarska 53, 656 91, Brno, Czech Republic

'Institute of Medical Genetics and Genomics, Faculty of Medicine, Masaryk University, Kamenice 5, 62500, Brno, Czech Republic Corresponding author: Lumir Kunovsky, e-mail: lumir.kunovsky@gmail.com

\section{BACKGROUND}

Acromegaly is a rare disease with incidence of approximately 3-5 persons per $1,000,000$ (ref. $^{1-3}$ ). This disorder is characterized by hypersecretion of growth hormone $(\mathrm{GH})$, which is usually caused by a pituitary adenoma ${ }^{2,4}$. This leads to overgrowth of almost all tissues in the body, most especially of acral and soft tissues, and to visceromegaly ${ }^{5}$. Multisystemic complications develop in acromegalic patients due to high GH and insulin-like growth factor-1 (IGF-1) levels, and these include joint pain, diabetes mellitus, hypertension, heart and respiratory failure, as well as disorders of the gastrointestinal (GI) system ${ }^{2,3}$. GI manifestations associated with acromegaly include adenomatous polyps, colon carcinoma, dolichocolon, and dysmotility (prolonged bowel transit time and impaired relaxation of the lower oesophageal sphincter [LES]) ( ref. $\left.^{4}\right)$.

Acromegaly is associated with decreased survival rate ${ }^{6}$. Acromegalic patients experience mortality due to cardiovascular disease in $60 \%$ of cases, respiratory disorders in 
$25 \%$ of cases, and neoplasms in $15 \%$ of cases ( ref. $^{3,7}$ ). This survival rate can be improved by successful surgical and adjunctive therapy ${ }^{3}$.

Although acromegaly occurs sporadically in $95 \%$ of all cases, almost $50 \%$ of childhood-onset cases have an identifiable genetic background, most commonly in the form of mutations in the genes encoding aryl hydrocarbon receptor interacting protein $(A I P)$ or G-protein coupled receptor 101 (GPR101) ( ref. $\left.^{8}\right)$. In addition, mutations in genes such as multiple endocrine neoplasia type 1 (MEN1); cyclin-dependent kinase inhibitor 1B $(C D K N 1 B)$; protein kinase A regulatory subunit type I alpha (PRKARIA); genes of the succinate dehydrogenase family $\mathrm{A}, \mathrm{B}, \mathrm{C}$, and $\mathrm{D}(S D H x)$; and the adenylate cyclase stimulatory protein alpha subunit $(G N A S)$ also have been associated with acromegaly/gigantism ${ }^{8}$.

Achalasia is an oesophageal motility disease characterized by aperistalsis of the oesophagus and impaired LES relaxation ${ }^{9,10}$. This disorder is caused by a degeneration of the myenteric plexus, but the aetiology of this degeneration remains unclear ${ }^{11}$. It is assumed that the plexus degeneration arises from a genetic predisposition caused by a viral infection and/or autoimmune process ${ }^{9,11}$. The incidence of this disease varies worldwide from 0.27 to 1.63 per 100,000 (ref. $^{12-17}$ ).

The diagnosis is based on clinical symptoms, endoscopy, high-resolution oesophageal manometry (HRM), and/or swallow radiography. Treatment can be conservative, endoscopic, or surgical ${ }^{11,18}$.

Achalasia can develop independently or as a part of Allgrove (Triple A) syndrome (i.e., adrenal insufficiency, achalasia, and alacrimia) (ref. ${ }^{19}$ ). In the latter case, association with mutations in the $A A A S$ gene has been identified $^{20}$.
The aims of this study were to analyse the genes associated with acromegaly and achalasia in a woman with both of these diseases, to find their aetiopathogenetic factors, and to suggest some explanations for the co-incidence of acromegaly and achalasia.

\section{CASE PRESENTATION}

We present a female whose history consists solely of recurrent superficial venous thrombosis of the lower extremities. No hypercoagulation syndrome was noted. In the family history there was no oesophageal disease or acromegaly. The patient has a monozygotic twin. At 30 years of age (in 2008), a multinodular thyroid gland with hyperplastic colloid nodules was identified, resulting 1 year later in a total thyroidectomy (preoperative values of thyroid gland hormones: thyroid stimulating hormone $1.07 \mathrm{mU} / \mathrm{L}$, thyroxine $12.86 \mathrm{pmol} / \mathrm{L})$.

In 2009 (at 31 years), an investigation for oesophageal dysmotility was performed due to dysphagia. Achalasia was identified by manometry with characteristic findings (Fig. 1). Treatment was started with balloon dilation of the oesophagus, but the effect was only temporary. The control swallow radiograph can be seen in Fig. 2. A laparoscopic Heller myotomy (LHM) with Nissen-Rossetti fundoplication was performed. After this procedure, the patient recovered without any signs of dysphagia.

In 2016 (at 38 years of age), acromegaly was suspected because the typical acromegalic changes of the face (acral growth) as well as of the lower and upper extremities were observed. The patient started to experience severe headaches. Her foot size had grown $5 \mathrm{~cm}$ in 7 years, she was not able to put a ring on her finger, and changes in

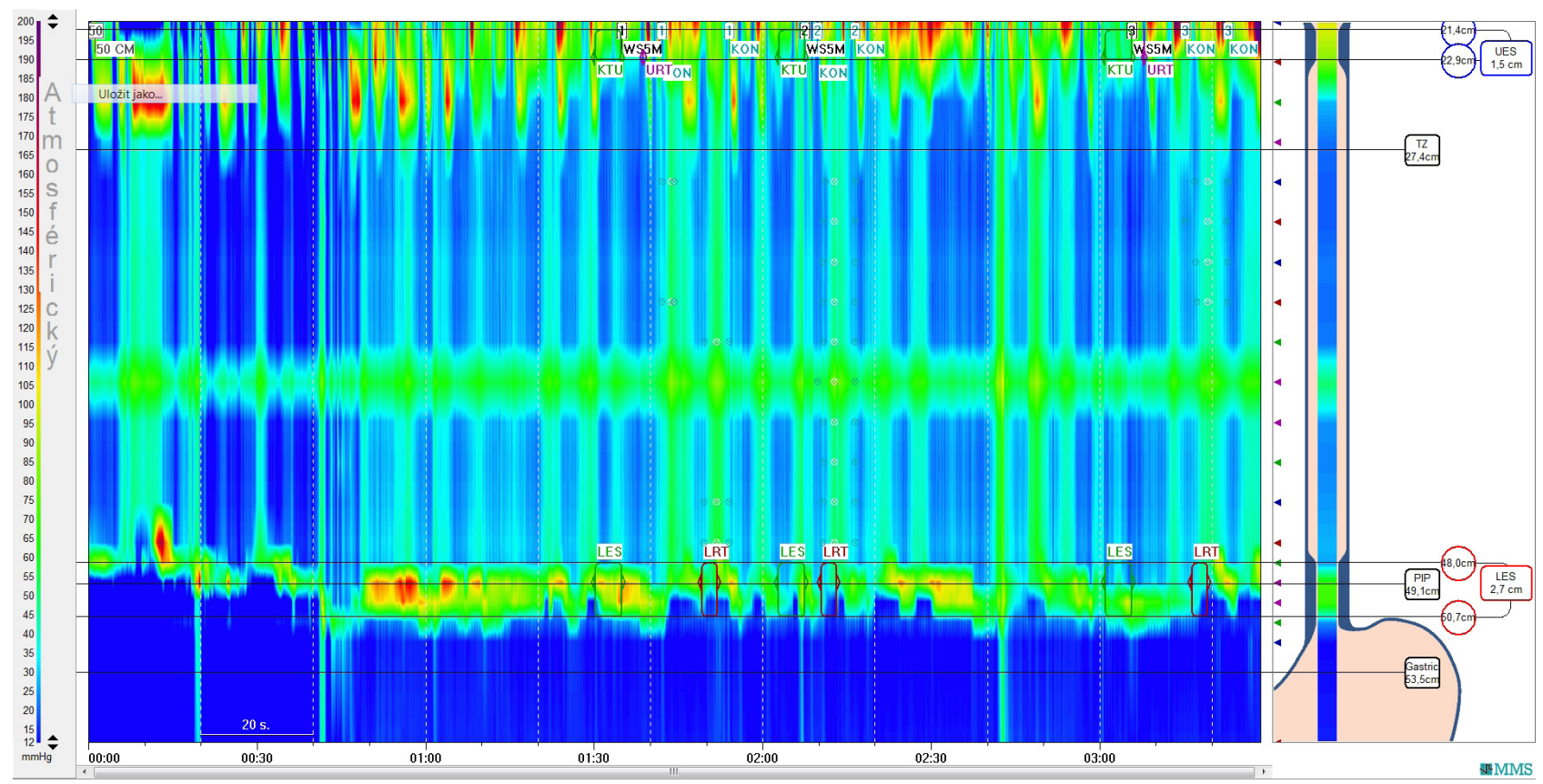

Fig. 1. HRM showing a typical view of achalasia type II - simultaneous contraction and non-relaxing LES during swallowing. 


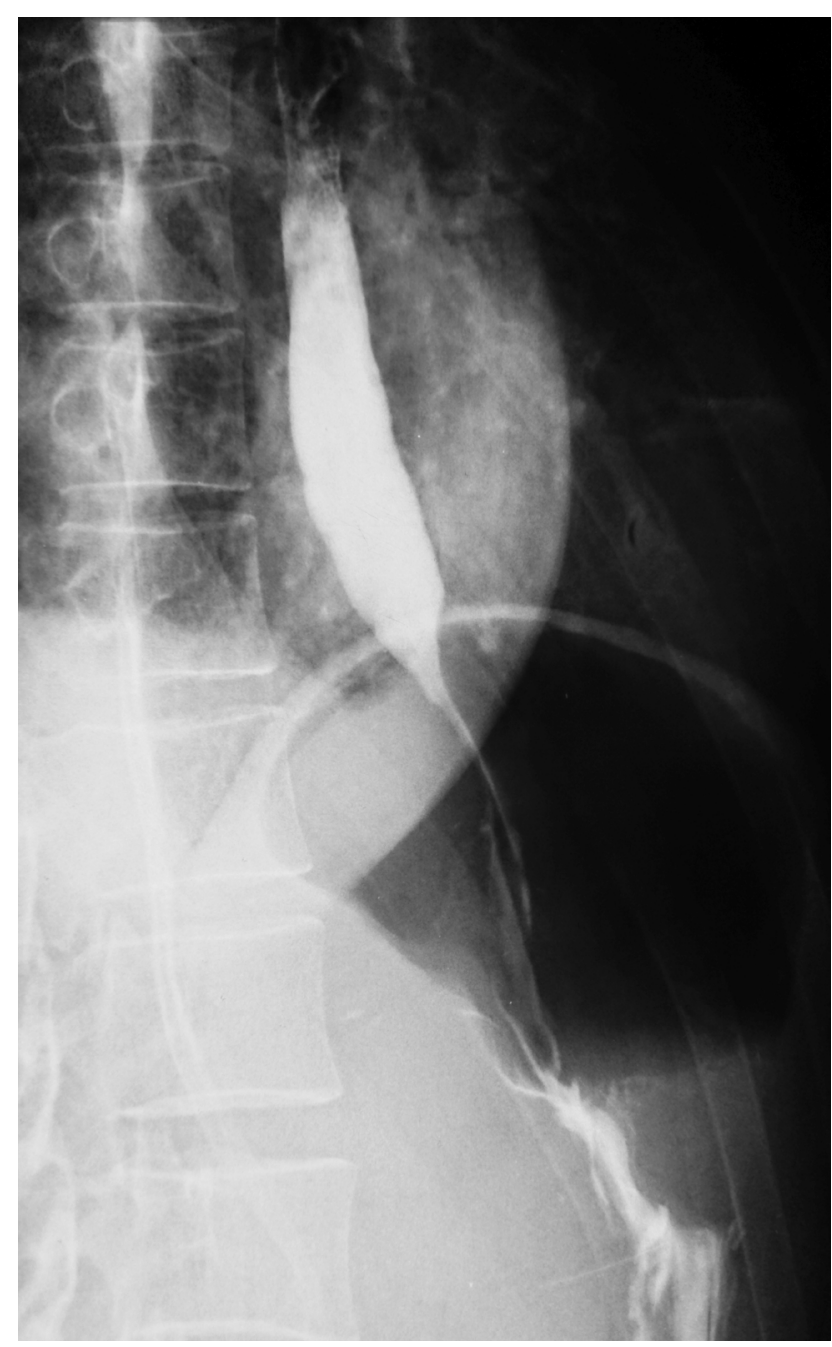

Fig. 2. The patient underwent sequential balloon dilations without treatment response. Fluoroscopy with barium revealed mild dilatation of the oesophagus with distal smooth, short-segment tapering.

the patient's voice also occurred. Laboratory tests gave reasons for suspicion of acromegaly $(\mathrm{GH} 48 \mathrm{mU} / \mathrm{L}$, reference range $0-24 \mathrm{mU} / \mathrm{L}$; IGF-1 $725 \mu \mathrm{g} / \mathrm{L}$, reference range $109-284 \mu \mathrm{g} / \mathrm{L})$. The diagnosis of acromegaly was confirmed by serum $\mathrm{GH}$ concentrations assessed during an oral glucose tolerance test $(\mathrm{GH} 48 \mathrm{mU} / \mathrm{L}$ at beginning of test, $28 \mathrm{mU} / \mathrm{L}$ after $1 \mathrm{~h}$ of glucose application, $22 \mathrm{mU} / \mathrm{L}$ after $2 \mathrm{~h}$. The test was positive due to inadequate suppression of $\mathrm{GH}$ after application of $75 \mathrm{~g}$ of glucose. Magnetic resonance imaging $(\mathrm{MRI})$ revealed a macroadenoma of the non-enhanced pituitary gland $14 \times 10 \times 9 \mathrm{~mm}$ in size (Fig. 3a, 3b). The optic chiasm was not affected by the lesion. The patient was referred to neurosurgery and transnasal endoscopic extirpation of the adenoma was performed. The histopathology of the adenoma of the pituitary gland can be seen in Fig. $4 \mathrm{a}$ and $4 \mathrm{~b}$. The patient
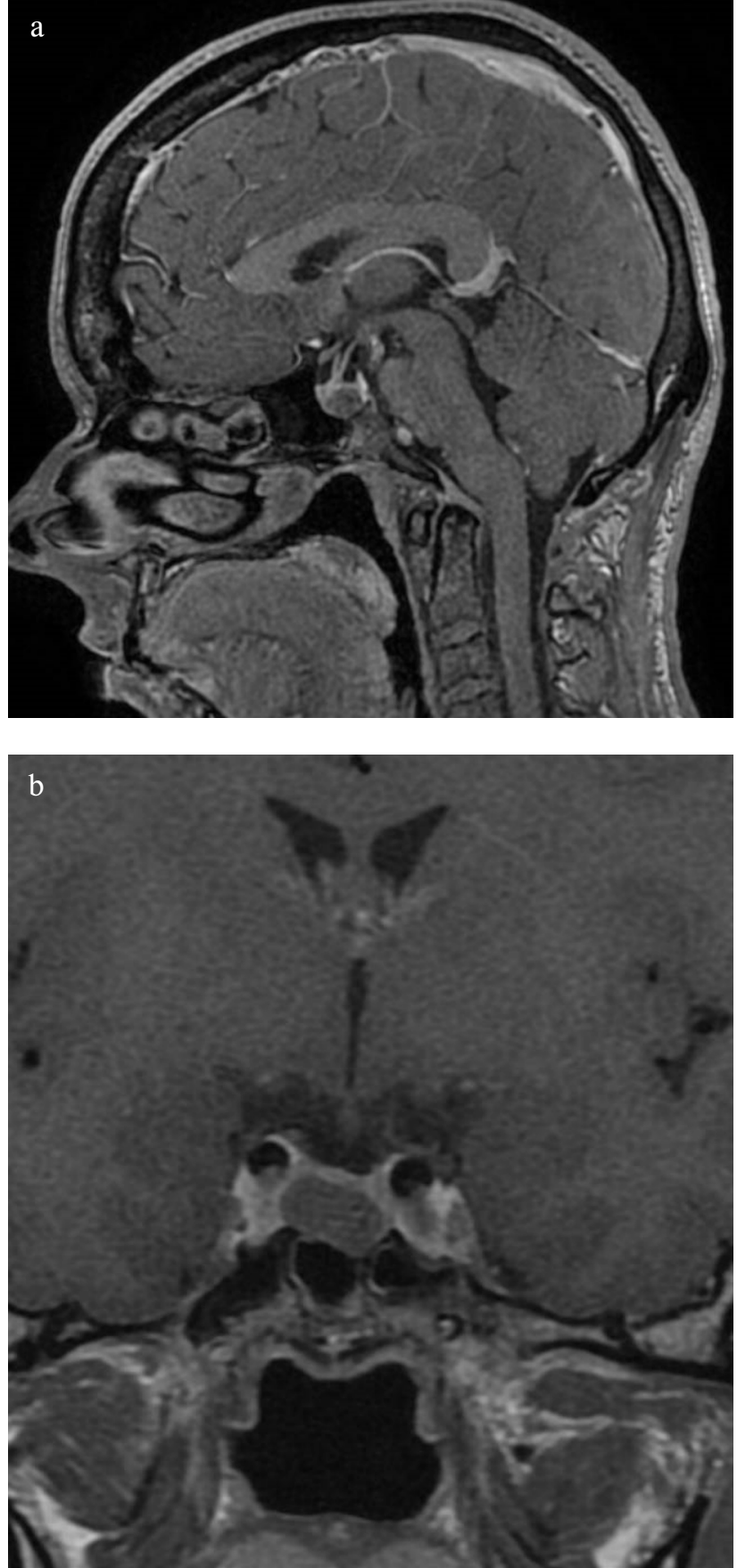

Fig. 3a, 3b. Contrast-enhanced MRI - T1WI. Sagittal section (a), coronal section (b) showing a non-enhanced pituitary mass $14 \times 10 \times 9 \mathrm{~mm}$ in size. The optic chiasm was not affected by the lesion.

was discharged 8 days after surgery. The control MRI showed a small residual amount of adenoma tissue, which was successfully treated by gamma knife radiosurgery. Subsequently, the levels of GH and IGF-1 normalized (hormone levels after surgery GH 7 mU/L, IGF-1 345 $\mu \mathrm{g} / \mathrm{L}$; after radiotherapy GH $15 \mathrm{mU} / \mathrm{L}$, IGF-1 $189 \mu \mathrm{g} / \mathrm{L} ; 1$ year after radiosurgery $\mathrm{GH} 8 \mathrm{mU} / \mathrm{L}, \mathrm{IGF}-1178 \mu \mathrm{g} / \mathrm{L})$. We also performed a colonoscopy, with normal findings. An echocardiography showed normal heart function without signs of cardiomyopathy or valve dysfunction. 
Table 1. Sequences of the specific primers used for PCR amplification of all 16 exons of the AAAS gene (NM_015665).

\begin{tabular}{|c|c|c|}
\hline $\begin{array}{l}\text { Location of exons } \\
\text { (NM_015665) }\end{array}$ & Forward primer & Reverse primer \\
\hline $\begin{array}{l}1 . .286 \\
287 \ldots 414\end{array}$ & 5'-GTGACCCAGGAAACCCTTT-3' & 5'-AGAAGCTTTGGAGGTCTGTC-3' \\
\hline $\begin{array}{l}415 \ldots 470 \\
471 \ldots 562\end{array}$ & 5'-AAGGATAGGAATGAGGGCAGA-3' & 5'-AAGCTGACCCACATTTTCCTC-3' \\
\hline $\begin{array}{l}563 \ldots 609 \\
610 \ldots 708 \\
709 \ldots 852\end{array}$ & 5'-AACTCTCAGGCCAAGGTAAG-3' & 5'-CCAGTGTGTCCTGTGTCTATC-3' \\
\hline $\begin{array}{l}853 \ldots 973 \\
974 \ldots 10981099 \ldots 1159 \\
1160 \ldots 1250\end{array}$ & 5'-TGACCACCCCAAATACTGAA-3' & 5'-TTCTGACTCCACATCCTCTGT-3' \\
\hline $\begin{array}{l}1251 \ldots 13441345 \ldots 1412 \\
1413 \ldots 14941495 \ldots 1579 \\
1580 \ldots 1837\end{array}$ & 5'-CAACTCCCTGGAAAAGACAGA-3' & 5'-CTTGCAAGAACCTCTCTGCT-3' \\
\hline
\end{tabular}

Table 2. Common polymorphisms in the genes associated with acromegaly found in the patient.

\begin{tabular}{llllllcc}
\hline Gene & Variant cDNA & $\begin{array}{l}\text { Variant } \\
\text { protein }\end{array}$ & $\begin{array}{l}\text { RefSeq } \\
\text { accession }\end{array}$ & dbSNP & $\begin{array}{l}\text { Hetero/ } \\
\text { homozygous }\end{array}$ & $\begin{array}{l}\text { MAF in EU } \\
\text { population (\%) }\end{array}$ & Method \\
\hline MEN1 & c.1621A>G & p.T541A & NM_000244 & rs2959656 & homozygous & 99.0 & NGS panel \\
MEN1 & c.1314T>C & p.H438H & NM_000244 & rs540012 & homozygous & 100.0 & NGS panel \\
AIP & c.682C>A & p.Q228K & NM_003977 & rs641081 & homozygous & 100.0 & NGS panel \\
AIP & c.920A>G & p.Q307R & NM_003977 & rs4930199 & homozygous & 100.0 & NGS panel \\
CDKN1B & c.326T>G & p.V109G & NM_004064 & rs2066827 & heterozygous & 24.3 & NGS panel \\
PRKAR1A & c.998G>A & p.S333N & NM_002734 & rs9789047 & heterozygous & 20.6 & NGS panel \\
PRKAR1A & c.349-5dupT & - & NM_002734 & rs3841514 & heterozygous & 24.7 & NGS panel \\
PRKAR1A & c.770-24G>A & - & NM_002734 & rs2302230 & homozygous & 68.0 & NGS panel \\
PRKAR1A & c.892-34G>T & - & NM_002734 & rs2302231 & homozygous & 67.8 & NGS panel \\
SDHB & c.201-36G>T & - & NM_003000 & rs1022580 & homozygous & 97.2 & NGS panel \\
SDHB & c.18C>A & p.A6A & NM_003000 & rs2746462 & homozygous & 97.2 & NGS panel \\
GPR101 & c.370G $>\mathrm{T}$ & p.V124L & NM_054021 & rs1190736 & homozygous & 38.0 & Sanger sequencing \\
\hline
\end{tabular}

Minor allele frequency (MAF) refers to the frequency at which the second most common allele occurs in a given population.

\section{GENETIC ANALYSIS}

Germline DNA was isolated from leukocytes of peripheral blood by a standard protocol (phenol-chloroform method).

An original protocol was created for identifying mutations in the $A A A S$ gene associated with achalasia. Five pairs of specific polymerase chain reaction (PCR) primers were designed to amplify all 16 exons of the $A A A S$ gene (NM_015665) (Table 1). The PCRs were performed using REDTa $q^{\circledR}$ DNA polymerase (VWR, Radnor, PA, USA) in a $20 \mu \mathrm{L}$ reaction volume. The conditions for PCR were as follow: $95^{\circ} \mathrm{C}$ for the $2.5 \mathrm{~min}$ activation/denaturation step, followed by 40 cycles of $95{ }^{\circ} \mathrm{C}$ for $20 \mathrm{~s}, 60^{\circ} \mathrm{C}$ for $20 \mathrm{~s}, 72$ ${ }^{\circ} \mathrm{C}$ for $60 \mathrm{~s}$, with a final extension for $5 \mathrm{~min}$. Amplicons were purified by ExoI-FastAP (Thermo Fisher Scientific, Waltham, MA, USA). The mixtures were incubated at $37{ }^{\circ} \mathrm{C}$ for $15 \mathrm{~min}$ and at $85^{\circ} \mathrm{C}$ for $15 \mathrm{~min}$ to inactivate the enzymes, followed by sequencing with a BigDye
Terminator v.3.1 (Applied Biosystems, Foster City, CA, USA). Sequencing reactions were purified by EDTA/ethanol precipitation, resuspended in $15 \mu \mathrm{L}$ Hi-Di Formamide (Applied Biosystems), then sequenced on an automated ABI 3500 Genetic Analyzer (Applied Biosystems). Finally, sequences were compared using BioEdit v.7.0.9.0 (ref. ${ }^{21}$ ) with a standard sequence NM_015665 of the $A A A S$ gene obtained from the GenBank database.

There were two differences between the patient's sequence and the standard sequence NM_015665 of the $A A A S$ gene. First, the patient was heterozygous (AT) in position 195 (counting according to the translated sequence). Second, the T base of the C855T single nucleotide polymorphism (SNP), known as rs1546808, was recorded on both strands (Supplementary data 1 ).

For identification of mutations in genes associated with acromegaly/gigantism in the patient, an NGS-based panel targeting 345 genes was used. This panel is customized and primarily designed for detecting mutations in 

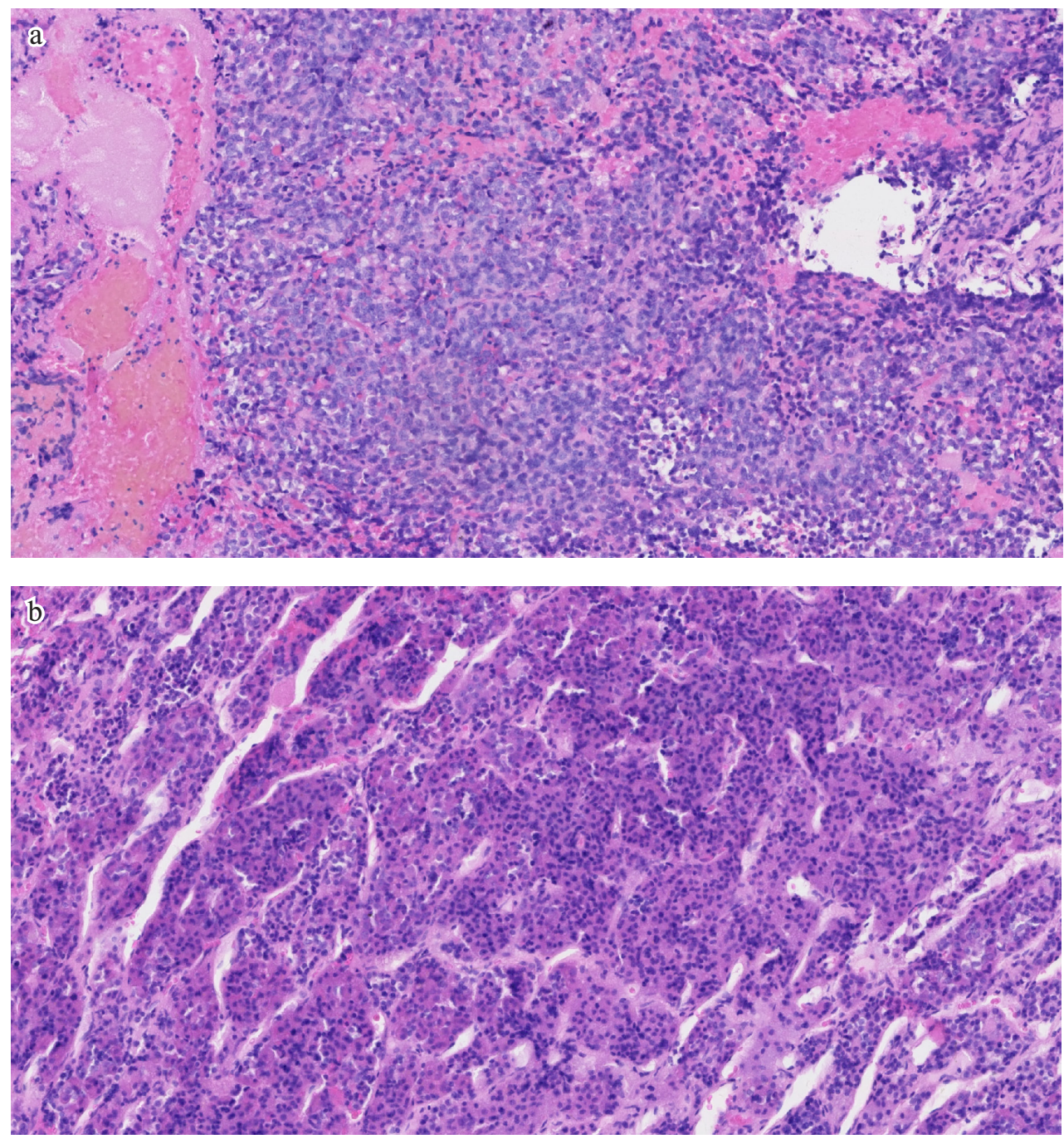

Fig. 4a, 4b. Histopathology of the adenoma of the pituitary gland. A tumour consisting of trabeculae of polygonal cells with uniform, round to oval nuclei with smooth chromatin and amphophilic cytoplasm. No mitoses or necrosis present. Haematoxylin-eosin staining (200×).

genes associated with a predisposition towards various cancers, but it includes five genes that have been found to be mutated also in patients with acromegaly: $A I P, M E N 1$, $C D K N 1 B, P R K A R 1 A$, and $S D H B$ (ref. ${ }^{8}$ ). The patient's DNA extracted from the leukocytes was used as input material for the assay, followed by the preparation of sequencing libraries using SureSelectXT HS Target Enrichment System (Agilent, Santa Clara, CA, USA) according to the manufacturer's protocol and sequencing on a NextSeq 500 device (Illumina, San Diego, CA, USA). In the bioinformatic analysis, sequencing reads in fastq format were mapped to the human reference genome GRCh37 with the bwa mem algorithm. PCR duplicates were marked in the resulting alignments with the Fgbio toolkit, which can utilize unique molecular identifiers included in the library. The quality of the final alignments was checked in respect to region coverage and depth and was used to assess germline variants. To minimize false negative calls, three different tools were used for germline variant calling (i.e., GATK HaplotypeCaller, VarDict, and Strelka2) and resulting variants were merged. Merged variants were annotated using the VEP annotation tool, which includes
PolyPhen and SIFT scores for variant structural impact and reports co-located variants from several databases (snpDB, COSMIC, HGMD, NHLBI_ESP, and ClinVar).

Variants were filtered manually. Examination using this NGS-based panel revealed only common polymorphisms in the genes of interest in our patient (reported in Table 2).

Because no pathogenic mutation was found using the NGS panel, we decided to take a closer look at the remaining genes that have been related to acromegaly: GPR101 and GNAS.

Amplification and sequencing primers were designed (primer sequences and PCR conditions are available in Supplementary data 2) for the whole coding region of the GPR 101 gene and the most common mutations in codons R201 and Q227 of the GNAS gene.

DNA extracted from the formalin-fixed paraffin-embedded (FFPE) tissue sample of the pituitary macroadenoma and of the thyroid gland was used for identifying somatic mutations in the GNAS gene.

Sequencing was performed on an ABI 3500 Genetic Analyzer device (Applied Biosystems) and sequences 


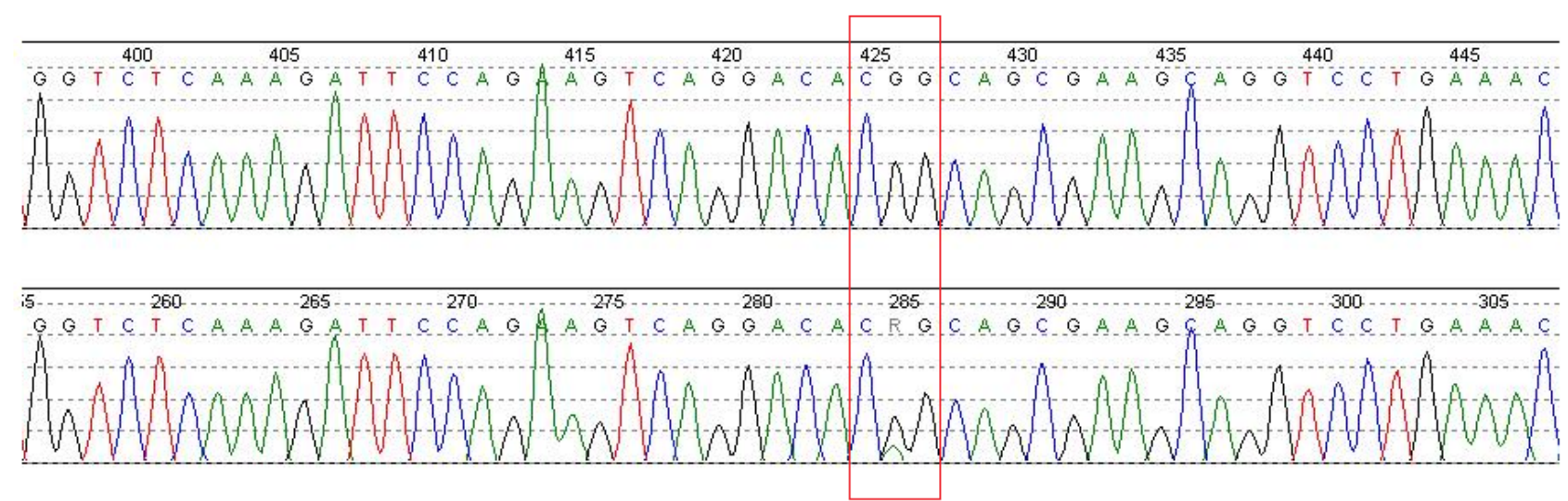

Fig. 5. Part of the GNAS gene sequence - reference sequence NM_000516 (upper row), patient sequence with the c.601C >T/p. R201C mutation (lower row). The red square is a codon.

were analysed using the Mutation surveyor V4.0.9 software (SoftGenetics, State College, PA, USA).

The common polymorphism c.370G $>$ T/p.V124L (NM_054021, rs1190736; see Table 2) was found using Sanger sequencing, while sequencing of the GNAS gene revealed the somatic mutation c.601C $>$ T/p.R201C (NM_000516, rs 11554273; Fig. 5) in tissue of the pituitary macroadenoma only but not in that of the thyroid gland. Peripheral blood samples were obtained from the patient's monozygotic twin, mother, and father. DNA from leukocytes was extracted and the GNAS gene was analysed. No pathogenic mutation was found in this gene within the germline DNA of the patient's relatives.

\section{DISCUSSION AND CONCLUSION}

The diagnosis of achalasia is based on clinical symptoms (dysphagia, regurgitation, retrosternal pain, vomiting, and weight loss), endoscopy, HRM, and/or swallow radiography. Treatment can be conservative (botulinum toxin, pneumatic dilation, or medical therapy), endoscopic (peroral endoscopic myotomy [POEM]), or surgical (LHM) (ref. ${ }^{11,18}$ ). The best long-term results in therapy are achieved by pneumatic dilation or LHM (ref. ${ }^{18,22}$ ). Long-term follow-up studies to evaluate the effectiveness of POEM are needed ${ }^{23,24}$. The main limitation of POEM may be its non-association with any anti-reflux procedure, which is in contrast to LHM (ref. ${ }^{24}$ ). Our patient achieved excellent postoperative results with LHM and the dysphagia disappeared.

The clinical manifestations of acromegaly usually develop slowly and the diagnosis is often determined late (from 4 years to more than 10 years after onset) (ref. ${ }^{3}$ ). So it is possible also in our patient that the acromegaly could already have started even before the diagnosis of achalasia. The average onset of the disease is at 49 years, with no difference by gender ${ }^{25}$. Because of the increased morbidity and mortality in acromegalic patients, early diagnosis of the disease is critical ${ }^{6}$. Making a diagnosis generally starts with a clinical suspicion (most typically acral growth and changes, as well as increased shoe and/ or ring size). A diagnosis of acromegaly is confirmed, however, by high levels of GH and IGF-1 (ref. ${ }^{2,3}$ ).

Due to the excess of GH and IGF-1, soft tissue hypertrophy involving the GI organs occurs in acromegalic patients ${ }^{1}$. This results in an enlargement of the GI organs. For example, dolichocolon is often observed in patients with acromegaly. George et al. ${ }^{5}$ reported the case of an acromegalic patient with megaduodenum, where the destruction of neurons within the plexuses was mentioned as the possible aetiological cause.

Higher prevalence of colorectal neoplasm, prolonged bowel transit time, and dysmotility of the entire GI tract (including the oesophagus) have been described. BaldyWaligorska et al. ${ }^{26}$ stated that long-lasting uncontrolled acromegaly significantly increased the risk of malignant neoplasms. Higher prevalence of colorectal neoplasm in acromegalic patients has been reported in many studies $^{1,3,27}$. Because of an increased risk of colorectal neoplasms, more frequent endoscopic screening is recommended ${ }^{27}$.

Prolonged exposure to high levels of GH and IGF-1 also affects the heart muscle. Dilation and hypertrophy of the heart (dilated cardiomyopathy) can develop ${ }^{28}$.

Oesophageal dysmotility and impaired LES relaxation in acromegalic patients have been described previously ${ }^{4,29}$. Some theories of motility disorders have been associated with low levels of nitric oxide (as the main neurotransmitter in the GI tract causing smooth muscle relaxation). Another theory of oesophageal motility dysfunction considers alterations in GI hormones (ghrelin and somatostatin) and GH levels ${ }^{4}$.

An association between dilation and hypertrophy of soft tissue and muscle tissue (oesophageal dysmotility, prolonged bowel transit time, dolichocolon, megaduodenum, and dilated cardiomyopathy) in achalasia aetiology should be considered. Hypertrophy of the soft tissue possibly causes the destruction of neuron plexuses, which can be one of the possible aetiologies of achalasia.

A co-occurrence of achalasia and oesophageal cancer has also been reported ${ }^{23}$. A relationship between food stasis, chronic inflammation, and a potentially increased risk of carcinoma development has also been described ${ }^{30,31}$. 
Based on these reports, a thorough endoscopic surveillance was required for our patient having co-occurrence of acromegaly and achalasia.

Some authors have reported an increased incidence of achalasia with autoimmune thyropathy ${ }^{32}$. This strengthens the theory of achalasia's having an autoimmune disease aetiology. In our case, the thyroid gland of the patient had also been treated. Nevertheless, no autoimmune thyroid disorder was revealed.

A possible association of achalasia and polyglandular autoimmune syndrome type 2 (autoimmune Addison's disease in combination with autoimmune thyroid disease and/or type 1 diabetes mellitus) is also described in the literature ${ }^{10,33}$. Moreover, there are several reports associating megaesophagus with adrenocortical insufficiency and other autoimmune endocrine diseases in $\operatorname{dog} \mathrm{s}^{34,35}$. Fritzen et al. ${ }^{36}$ in 1996 even described a human with megaesophagus and autoimmune adrenal failure as a feature of autoimmune polyglandular syndrome type 2 . In addition to these findings, dysphagia and vomiting are also characteristic in untreated Addison patients, but they usually resolve after hormone substitution ${ }^{33,36}$. It nevertheless remains unclear whether low cortisol levels could possibly play a role in the development of lower oesophagus dysmotility or achalasia. Moreover, our patient had normal cortisol levels.

Because of the possibility that our patient with achalasia might be suffering from Allgrove (Triple A) syndrome, the $A A A S$ gene was analysed. This gene encoding the ALADIN protein (WD-repeat protein) (ref. ${ }^{20}$ ) is located on chromosome 12 and is strongly associated with Allgrove syndrome ${ }^{37}$. In our patient, however, we found no clinical signs for this syndrome (the patient did not suffer from alacrimia or adrenal insufficiency), nor did we find the typical mutations to confirm the presence of this syndrome. We found a novel mutation A195T in exon 2 leading to the synonymous substitution (Thr65Thr). There was also a difference between the patient's and the standard sequence in position 855 (Phe285Phe). The T allele of SNP rs 1546808 occurs with high frequency in the European Caucasian population (99.5\%, https://www. ncbi.nlm.nih.gov/projects/SNP/snp_ref.cgi?rs=1546808), however, and therefore these findings are not significant in relation to this syndrome.

In addition, we found no "causal" mutations in genes previously associated with acromegaly (i.e., MEN1, AIP, $C D K N 1 B, P R K A R 1 A, S D H B, G P R 101)$ and only common polymorphisms were detected in these genes in our patient. Activating mutations in the GNAS gene, with a frequency of about $40 \%$, are the most common somatic mutations in acromegaly. Mutation c.601C > T/p.R201C in the GNAS gene leads to a loss of GTPase activity of the G-stimulatory protein alpha subunit while leaving adenyl cyclase stimulatory activity intact. The result of constitutive activation and increased intracellular cAMP levels could probably lead to somatotroph hyperplasia/adenoma and $\mathrm{GH}$ hypersecretion ${ }^{38}$. Genetic examination proved that our patient had sporadic acromegaly with no evidence for family-based acromegaly. Further, we suppose the co-occurrence of acromegaly with the previously di- agnosed achalasia, but the aetiopathogenesis of this state is unclear.

Co-incidence of acromegaly and McCune-Albright syndrome (MAS) has been described in the literature. Acromegaly affects around 20-30\% of MAS patients ${ }^{39}$. MAS includes the triad of poly/monostotic fibrous dysplasia, café-au-lait spots, and hyperfunctioning endocrinopathies (precocious puberty) $\left(\right.$ ref. $\left.^{40}\right)$. In our patient, we found no café-au-lait spots, fibrous dysplasia of the bones, or precocious puberty.

\section{CONCLUSION}

In conclusion, acromegaly, with its typical overproduction of $\mathrm{GH}$, affects all systems of the human body. Gastrointestinal dysmotility in acromegalic patients (i.e., impaired relaxation of the LES) has been previously described. We report the first co-occurrence of acromegaly and achalasia, and we suggest the association of acromegaly and soft muscle tissue hypertrophy as one of the factors contributing to achalasia development. If one of these two diagnoses is determined, therefore, presence of the other should be considered. Moreover, an increased risk of malignancy (oesophageal and colorectal) should also be considered. More studies are needed to clarify the aetiology and association of these two diseases.

\section{ABBREVIATIONS}

GH, Growth hormone; GI, Gastrointestinal; HRM, High-resolution oesophageal manometry; IGF-1, Insulinlike growth factor-1; LES, Lower oesophageal sphincter; LHM, Laparoscopic Heller myotomy; MAS, McCuneAlbright syndrome; POEM, Peroral endoscopic myotomy; SNP, Single nucleotide polymorphism.

Acknowledgements: We acknowledge CF Genomics, supported by NCMG research infrastructure (LM2018132 funded by MEYS CR), for its support in obtaining scientific data presented in this paper. The study was supported by funds provided by the Faculty of Medicine, Masaryk University to junior researcher Petra Borilova Linhartova, supported by the Ministry of Health of the Czech Republic, grant no. NU20-03-00126, and supported by the Ministry of Health of the Czech Republic - conceptual development of research organization ( $\mathrm{FNBr}$, 65269705 , SUp 3/21). The funder has no role in the design of the study, in the collection, analysis, and interpretation of data, or in writing the manuscript.

Author contributions: JD: writing, main author, conception and design of the work, literature search; LK: consultant, writing, text editor, conception and design of the work, literature search, figures; RK, KS, PJ, TN, KM, TA, FM, ZK, and JV: consultants, text editors, conception and design of the work, figures, literature search; DS: histopathological examination; MZ, JL, HPN, OS: text editors, genetic analyses; LIH: consultant and text editor; PBL: 
design of genetic analysis, literature search, text editor. All authors made critical revisions and gave their final approval for publishing.

Conflict of interest statement: The authors state that there are no conflicts of interest regarding the publication of this article.

\section{REFERENCES}

1. Colao A, Ferone D, Marzullo P, Lombardi G. Systemic complications of acromegaly: epidemiology, pathogenesis, and management. Endocr Rev 2004;25(1):102-52.

2. Melmed S. Acromegaly pathogenesis and treatment. J Clin Invest 2009;119(11):3189-202.

3. Lugo G, Pena L, Cordido F. Clinical Manifestations and Diagnosis of Acromegaly. Int J Endocrinol 2012;2012:540398.

4. Ilhan M, Danalioglu A, Turgut S, Karaman O, Arabaci E, Tasan E. Acromegaly can be associated with impairment of LES relaxation in the oesophagus. Endokrynol Pol 2015;66(4):308-12.

5. George B, Vinay D, Moolechery J, Mathew V, Anantharaman R, Ayyar $\mathrm{V}$, Bantwal G. Megaduodenum in a patient with acromegaly. Indian J Endocrinol Metab 2012;16(Suppl 2):S324-5.

6. Kršek M. Acromegaly: current view. Vnitr Lek 2015;61(10):900-4. (In Czech)

7. Holdaway IM, Rajasoorya RC, Gamble GD. Factors influencing mortality in acromegaly. J Clin Endocrinol Metab 2004;89(2):667-74.

8. Gadelha MR, Kasuki L, Korbonits M. The genetic background of acromegaly. Pituitary 2017;20(1):10-21.

9. Furuzawa-Carballeda J, Torres-Landa S, Valdovinos MÁ, Coss-Adame E, Martín Del Campo LA, Torres-Villalobos G. New insights into the pathophysiology of achalasia and implications for future treatment. World J Gastroenterol 2016;22(35):7892-907.

10. Amr BS, Mamillapalli C. Achalasia in a Patient with Polyglandular Autoimmune Syndrome Type II. Case Rep Gastroenterol 2015;9(2):160-64.

11. Ates F, Vaezi MF. The Pathogenesis and Management of Achalasia: Current Status and Future Directions. Gut Liver 2015;9(4):449-63.

12. Birgisson S, Richter JE. Achalasia in Iceland, 1952-2002: An Epidemiologic Study. Dig Dis Sci 2007;52(8):1855-860.

13. Farrukh A, DeCaestecker J, Mayberry JF. An epidemiological study of achalasia among the South Asian Population of Leicester, 19862005. Dysphagia 2008;23(2):161-64.

14. Gennaro N, Portale G, Gallo C, Rocchietto S, Caruso V, Costantini M, Salvador R, Ruol A, Zaninotto G. Esophageal achalasia in the Veneto region: epidemiology and treatment. Epidemiology and treatment of achalasia. J Gastrointest Surg 2011;15(3):423-8.

15. Sadowski DC, Ackah F, Jiang B, Svenson LW. Achalasia: incidence, prevalence and survival. A population-based study. Neurogastroenterol Motil 2010;22(9):e256-61.

16. Kim E, Lee H, Jung HK, Lee KJ. Achalasia in Korea: an epidemio logic study using a national healthcare database. J Korean Med Sc 2014;29(4):576-80.

17. Tebaibia A, Boudjella MA, Boutarene D, Benmediouni F, Brahimi $H$ Oumnia N. Incidence, clinical features and para-clinical findings of achalasia in Algeria: Experience of 25 years. World J Gastroenterol 2016;22(38):8615-623.

18. Esposito D, Maione F, D'Alessandro A, Sarnelli G, De Palma GD. Endoscopic treatment of esophageal achalasia. World J Gastrointest Endosc 2016;8(2):30-9.

19. Alhussaini B, Gottrand F, Goutet JM, Scaillon M, Michaud L, Spyckerelle C, Viola S, Lamblin MD. Clinical and manometric characteristics of Allgrove syndrome. J Pediatr Gastroenterol Nutr 2011:53(3):271-4.

20. Krumbholz M, Koehler K, Huebner A. Cellular localization of 17 natural mutant variants of ALADIN protein in triple A syndrome Shedding light on an unexpected splice mutation. Biochem Cell Biol 2006;84(2):243-49.
21. Hall, TA. BioEdit: a user-friendly biological sequence alignment editor and analysis program for Windows 95/98/NT. Nucleids Acids Symposium Ser 1999;41:95-98.

22. Torresan F, loannou A, Azzaroli F, Bazzoli F. Treatment of achalasia in the era of high-resolution manometry. Ann Gastroenterol 2015;28(3):301-08.

23. Moonen A, Boeckxstaens G. Current Diagnosis and Management of Achalasia. J Clin Gastroenterol 2014;48(6):484-90.

24. Familiari P, Greco S, Volkanovska A, Gigante G, Cali A, Boškoski I, Costamagna G. Achalasia: current treatment options. Expert Rev Gastroenterol Hepatol 2015;9(8):1101-14.

25. Hana V, Svancara J, Bandurova L, Brabec P, Cap J, Durovcová V, Dvorakova E, Hana V Jr., Jarkovcova Z, Kentos P, Klimes D, Krcma M, Krsek M, Lazurova I, Olsovska V, Podoba J, Pura M, Sasikova M, Stary K, Strenkova J, Siprova H, Steno J, Trejbalova L, Vanuga P, Wagnerova H, Weiss V, Zeman D, Dusek L, Marek J. Register of Sellar Tumors - RESET: Diagnostics and Therapy of Acromegaly in Czech and Slovak Republics in the $21^{\text {th }}$ Century. Diabetologie, Metabolismus, Endokrinologie a Výživa 2013;16(4):219-24. (In Czech)

26. Bałdys-Waligórska A, Krzentowska A, Gołkowski F, Sokołowski G, Hubalewska-Dydejczyk A. The prevalence of benign and malignant neoplasms in acromegalic patients. Endokrynol Pol 2010;61(1):2934.

27. Rokkas T, Pistiolas D, Sechopoulos P, Margantinis G, Koukoulis G. Risk of colorectal neoplasm in patients with acromegaly: a meta-analysis. World J Gastroenterol 2008;14(22):3484-9.

28. Nair AS, Nirale AM, Sriprakash K, Gopal TV. Dilated cardiomyopathy in acromegaly: Case report and anesthesia management. Anesth Essays Res 2013;7(3):411-4.

29. Marchese $M$, Spada $C$, Tringali $A$, lacopini F, Farniliari $P$, Belmonte M, Petruzziello L, Mntignani M, Costamagna G. Esophageal motility in 23 acromegalic patients. Digest Liver Dis 2006; 38: Supplement 1:S133.

30. Porschen R, Molsberger G, Kühn A, Sarbia M, Borchard F. Achalasia-associated squamous cell carcinoma of the esophagus: flow-cytometric and histological evaluation. Gastroenterology 1995; 108(2):545-9.

31. Streitz JM Jr, Ellis FH Jr, Gibb SP, Heatley GM. Achalasia and squamous cell carcinoma of the esophagus: analysis of 241 patients. Ann Thorac Surg 1995;59(6):1604-9.

32. Kroupa R, Starý K, Hep A, Suchánková J, Dolina J. Higher incidence of thyropathy in patients with oesophageal achalasia. Genetic, autoimmune, regional or just a random association?. Vnitr Lek 2008;54(4):341-5. (In Czech)

33. Kahaly GJ. Polyglandular autoimmune syndromes. Eur J Endocrinol 2009;161(1):11-20.

34. Bartges JW, Nielson DL. Reversible megaesophagus associated with atypical primary hypoadrenocorticism in a dog. J Am Vet Med Assoc 1992;201(6):889-91.

35. Bowen D, Schaer M, Riley W. Autoimmune polyglandular syndrome in a dog: a case report. J Am Anim Hosp Assoc 1986;22:649-53.

36. Fritzen R, Bornstein SR, Scherbaum WA. Megaoesophagus in a patient with autoimmune polyglandular syndrome Type II. Clin Endocrinol 1996;45(4):493-98.

37. Handschug K, Sperling S, Yoon SJ, Hennig S, Clark AJ, Huebner A. Triple A syndrome is caused by mutations in AAAS, a new WD-repeat protein gene. Hum Mol Genet 2001;10(3):283-90.

38. Landis CA, Masters SB, Spada A, Pace AM, Bourne HR, Vallar L. GTPase inhibiting mutations activate the alpha chain of Gs and stimulate adenylyl cyclase in human pituitary tumours. Nature 1989;340(6236):692-96.

39. Salenave S, Boyce AM, Collins MT, Chanson P. Acromegaly and McCune-Albright syndrome. J Clin Endocrinol Metab 2014;99(6):1955-69.

40. Dumitrescu CE, Collins MT. McCune-Albright syndrome. Orphanet J Rare Dis 2008;3:12.

\section{Supplemental Material:}

The online version of this article (doi: $10.5507 /$ bp.2021.040) offers supplemental material. 